\title{
Critical knowledge gaps in the Martian geological record: A rationale for regional-scale in situ exploration by rotorcraft mid-air deployment
}

\author{
Primary author and coauthors \\ W. Rapin ${ }^{1}$ (william.rapin@upmc.fr, +33769584256), A. Fraeman², B.L. Ehlmann ${ }^{2,3}$, A. \\ Mittelholz $^{4}$, B. Langlais ${ }^{5}$, R. Lillis ${ }^{6}$, V. Sautter ${ }^{1}$, D. Baratoux ${ }^{7}$, V. Payré ${ }^{8}$, A. Udry ${ }^{9}$, B. Horgan ${ }^{10}$, \\ J. Flahaut ${ }^{11}$, G. Dromart ${ }^{12}$, C. Quantin-Nataf ${ }^{12}$, N. Mangold ${ }^{5}$, S. Maurice ${ }^{7}$, J.T. Keane ${ }^{2}$, J. Bapst ${ }^{2}$. \\ Mid-air deployment (MAD) development team \\ J. Delaune ${ }^{2}$, J. Izraelevitz ${ }^{2}$, E. Sklyanskiy ${ }^{2}$, A. Schutte ${ }^{2}$, V. Scott ${ }^{2}$, Wayne Johnson ${ }^{13}$, L.A. \\ Young $^{13}$, S. Withrow ${ }^{3}$, J. Burdick ${ }^{3}$, M. Gharib ${ }^{3}$. \\ ${ }^{1}$ Sorbonne université/MNHN, IMPMC, CNRS, France \\ 2 Jet Propulsion Laboratory, California Institute of Technology \\ ${ }^{3}$ California Institute of Technology \\ ${ }^{4}$ University of British Columbia, Vancouver, Canada \\ ${ }^{5}$ Université de Nantes, Université d'Angers, LPGN, CNRS, France \\ ${ }^{6}$ University of California Berkeley \\ ${ }^{7}$ Université de Toulouse, IRAP, CNRS, France \\ ${ }^{8}$ Rice University \\ ${ }^{9}$ University of Nevada \\ ${ }^{10}$ Purdue University \\ ${ }^{11}$ CNRS/CRPG Nancy, France \\ ${ }^{12}$ Université Lyon, LGL, France \\ ${ }^{13}$ NASA Ames Research Center
}

A Science White Paper for the NASEM Planetary Science Decadal Survey (PSDS)

Pre-Decisional Information - For Planning and Discussion Purposes Only

\section{Endorsers}

Timothy A. Goudge (The University of Texas at Austin), Bob Craddock (Smithsonian Institution), Frances Rivera-Hernandez (Dartmouth College), Edward Cloutis (University of Winnipeg), Elizabeth Rampe (NASA JSC), Edwin Kite (University of Chicago), Munir Humayun (Florida State University), Adrian J. Brown (Plancius Research), Jesse Tarnas (Brown University), Devanshu Jha (MVJ College of Engineering (India)), Lucie Riu (ISAS/JAXA), Charles Cockell (University of Edinburgh), Vinciane

Debaille (Université Libre de Bruxelles (Belgium)), Charity Phillips-Lander (Southwest Research Institute), Alberto G. Fairén (Centro de Astrobiología (CSIC-INTA)), Jemma Davidson (Arizona State University), James W. Head (Brown University), Janice Bishop (SETI Institute), Kevin M. Cannon (University of Central Florida), Craig Hardgrove (Arizona State University), Pierre Beck (Université Grenoble Alpes), Jean-Pierre Lorand (CNRS/LPG Nantes (France)), Michael Bramble (JPL), Mark Salvatore (Northern Arizona University), Jeffrey Moersch (University of Tennessee), Etienne Médard (Université Clermont Auvergne (France)), Kevin Lewis (Johns Hopkins University), J.R. Skok (SETI Institute), Cecilia Leung (JPL), Jennifer Piatek (Central Connecticut State University), Andrea Hughes (Embry-Riddle Aeronautical University), Tim I. Michaels (SETI Institute), Scott Perl (JPL), Paul Byrne (North Carolina State University), Nathan Stein (Caltech), Candice Bedford (LPI) 
Summary: Mars oldest terrains hold the answers to key science questions, yet remain largely unexplored. In situ exploration by mid-air deployed rotorcrafts can uniquely answer these questions in the near future.

Mars's southern highlands are the oldest well-preserved record of major geological evolution on early Mars, and can solve key outstanding questions in planetary science today (Fig. 1):

(i) How did the Martian dynamo operate?

(ii) Which processes formed the early crust of Mars?

(iii) How did early environments evolve?

Yet, despite their importance, the oldest terrains have never been explored in situ primarily due to current entry descent and landing (EDL) technology limitations.

Orbital datasets (Fig. 1, 2) have provided important insights and testable hypotheses related to the above questions, but only in situ exploration offers the necessary tools to answer them and learn about Mars's evolution and habitability (e.g. Ehlmann et al., 2016).

In the decade to come, Mars-2020 and sample return will advance the search for biosignatures, as well as Martian petrology and geochronology, but yet findings will remain specific to Jezero crater. Addressing major global questions about paleomagnetism, magmatism/tectonism and paleoenvironments (Fig. 1) calls for other investigations. The most transformative approach requires in situ observations across regional scales (100s of $\mathrm{km}$ ) —well beyond the capabilities of modern, flagship-class rovers.

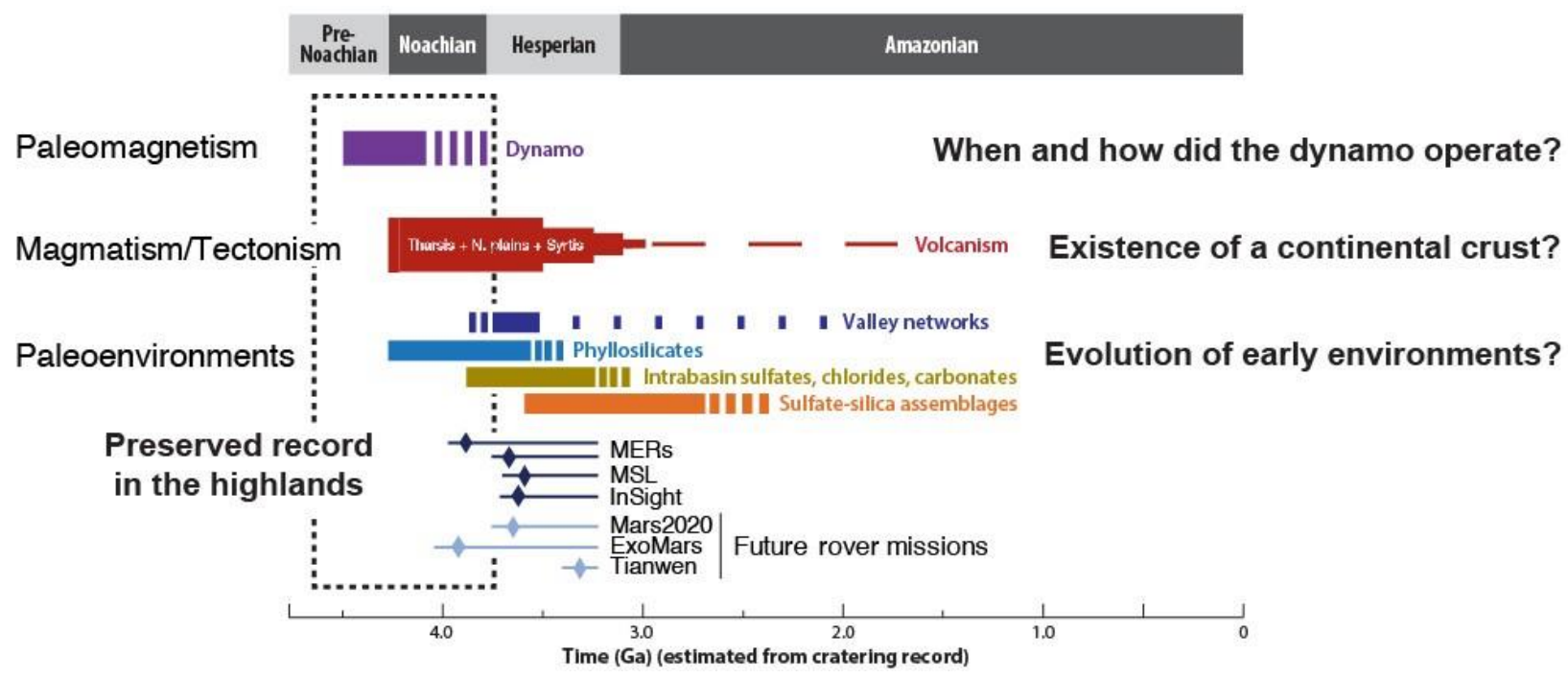

Figure 1: Timeline of major processes in Mars history and related outstanding questions (modified after Ehlmann \& Edwards, 2014). Estimated crater age of terrains for landed missions with error bars indicating uncertainty and extended to the right to highlight subsequent surface alteration.

In this white paper, we advocate addressing the aforementioned high priority science questions about Mars's ancient geological record and highlight the potential of mid-air deployed (MAD) rotorcrafts to do so (Delaune et al., 2020) with the unique capability of accessing ancient highlands terrains and performing in situ exploration at regional-scale, at breakthrough costs. 
Priority science question 1: When and how did the Martian core dynamo operate?

Establishing the timing, duration, and strength of the Martian magnetic field is critical to understanding a variety of important geologic processes - from the thermal evolution of Mars to the escape of Mars's atmosphere and long-term habitability.

Orbital sensing of the remanent magnetic field has revealed significant regional variations. While strong crustal fields are mostly found in the Southern hemisphere, the Northern hemisphere exhibits sparse and weak magnetization as detected from orbit (Fig. 2a). The origin of this hemispheric difference is unclear, and could be of endogenic (e.g. Stanley et al., 2008) or exogenic (e.g. Andrews-Hanna et al., 2008) origin, but either scenario would lead to major implications regarding the Martian present state and evolution.

Recently, the strongly magnetized surfaces of Terra Sirenum and Terra Cimmeria have revealed the complex thickness and density architecture of the martian crust in the highlands. These crustal structures may be the result of early crustal differentiation mechanisms and tectonic history, which remains to be documented and understood (Bouley et al., 2020).

New MAVEN data have been used to map remanent magnetization of the crust at higher resolution than earlier MGS measurements, reviving the debate on the longevity and strength of the core dynamo during the first billion years of Mars' history (Langlais et al., 2019). These models and low altitude data are consistent with a global dynamo field that operated both early $(\sim 4.5-4.1 \mathrm{Ga})$ and late $(\sim 3.7 \mathrm{Ga})$ in the martian history (Mittelholz et al., 2020).

The InSight fluxgate magnetometer also recently measured surface magnetic field strength 10times stronger than anticipated from orbital data, indicating small wavelength contributions to the magnetic field that cannot be seen from orbit (Johnson et al., 2020).

Using orbital data only, resolvable wavelengths are limited by the altitude of the magnetic field data (for MAVEN, as low as $\sim 135 \mathrm{~km}$ ). Current paleomagnetic reconstructions must rely on source geometry assumptions and layered crustal field models that have not been tested in situ yet.

There are currently no outcrop-scale lithological data on the remanent magnetic field that would help constrain the evolution of the core dynamo and correlate it with processes of crust formation and climatic evolution recorded in sedimentary sequences. These observations are impossible to perform using orbital assets and require in situ measurements.

These preliminary results highlight the need for further in situ observations spanning large regions of Mars's ancient southern highlands. Acquiring the first stratigraphic analysis of the remanent magnetic field on key Noachian outcrops would yield a significant impact on our understanding of early Mars evolution.

Further details on questions and objectives related to paleomagnetism can be found in the PSDS white paper of A. Mittelholz et al. 


\section{Priority science question 2: What processes formed the early Martian crust?}

There is a long-standing debate about the magmatic processes (e.g., magmatic ocean crystallization and overturn, volcanism involving mantle and/or crustal sources) involved in the formation of the crust and the formation of a chemically heterogeneous mantle in the first billion years of Mars history. The degree of crustal differentiation and the question of early crustal recycling has not been settled.

Yet this topic is fundamental for understanding the early Mars system because magmas drive the flux of volatiles from the interior, thus being a major contributor to climatic evolution. Understanding the early martian crust is also of astrobiological interest since early crustal materials governed the aqueous chemistry and habitability of surface environments, and also hosted a diversity of subsurface alteration processes.

Current knowledge on the composition of the Martian crust is largely based on orbital spectroscopy and meteorite analysis. Both indicate that the surface is predominantly basaltic. However, feldspathic and silica-rich magmatic rocks were observed for the first time in situ at Gale crater (Sautter et al., 2015). Combined with the identification of feldspar-rich rock signatures at various other locations in the ancient southern hemisphere (Fig. 2b; Carter \& Poulet, 2013; Wray et al., 2013), and the low average density of the crust there (Baratoux et al., 2014), it is possible that a significant fraction of the crust forming the southern highlands has a more evolved composition resembling the magmatic series of the Archean proto-continental crust (Sautter et al., 2015).

The current controversy about the nature of Mars's crust is related to the inherent challenges in characterizing the different types of surface composition via orbital global mapping (visible, nearinfrared, or thermal emission spectroscopy), and complicated by the crustal sampling offered by meteorites. Understanding the petrogenesis of magmatic rocks requires information on their texture, composition and mineral assemblages, as well as their geological setting, which can be only obtained together with in situ measurements.

Large scale geomorphic evidence also suggests that processes consistent with a form of early crustal recycling could have occurred, such as the orogeny associated with the Thaumasia plateau (Anguita et al., 2006; Dohm et al., 2009). Such models add to the collective lines of evidence towards major shifts in our understanding of early Mars history and need to be tested in situ.

In situ data on the lithology of key crustal components of the highlands are now needed to test models of geodynamic evolution that lead to the formation of the global crustal dichotomy (e.g. post-giant-impact processes) (Andrews-Hanna et al., 2008; Citron et al., 2018).

In addition, faults by tectonic activity provide outcrops exposing the early crust. These sites have been the most readily accessible record of geological history on Earth, while on Mars they could provide an even older well-preserved record $(>4.0 \mathrm{Ga})$ but have yet remained the most challenging to reach.

Further arguments supporting the need for in-situ investigations of Martian igneous composition are detailed in the PSDS white paper of A. Udry et al. 
Priority science question 3: What is the nature, persistence and habitability of environments on early Mars?

With the accumulation of increasingly more precise orbital data, our perception of Mars environmental history gradually changed from a planet dominated by the effect of volcanism and eolian processes to one rich with water-rock interactions producing large provinces of stratified rocks (Grotzinger \& Milliken, 2012). These sedimentary sequences, often several kilometers thick, are found in terrains of both Noachian and Hesperian age, all around Mars' surface (Fig. 2c). Yet, the vast majority of these sequences remain of unclear origin. Orbital data typically do not resolve fine sedimentary structures on outcrops that would typically allow to uniquely differentiate depositional environments (eolian, fluvial, lacustrine, volcanic).

A global inventory of observed textures of stratified outcrops from orbit highlighted six large groups of "orbital facies" (Grotzinger \& Milliken, 2012). This grouping suggests that only a few models of depositional and diagenetic environments would be enough to explain most of the sedimentary formations on Mars. This suggests that a small number of in situ missions can advance the documentation of different paleoenvironments with global significance.

For example, the Curiosity rover will be the first mission to analyze in detail a globally significant facies, the Laterally Continuous Sulfate, for several hundred meters of stratigraphy. Such an observation is a key to understanding the nature of environments in the Hesperian that lead to the formation of large sulfate deposits. The proximity and entanglement with other clay-bearing facies reflects the complexity of environmental changes in the Noachian-Hesperian global transition.

Timing of formation of alteration minerals is a key issue in understanding their relationship with the broader geological history. Global exposures of alteration minerals are found within both crustal or sedimentary settings in Noachian and Hesperian terrains, highlighting a potential diversity of formation mechanisms on early Mars (Ehlmann \& Edwards, 2014). In particular, the ancient highlands host chlorides, aluminum phyllosilicates and acid sulfate assemblages in lake basins, and serpentine- and chlorite-enriched rocks unvisited by any current or planned mission but significant globally.

The scenarios for the formation of alteration minerals found within exposed large ancient terrains remain non-unique because orbital data does not resolve fine-scale lithological context, mineral assemblages and stratigraphic distribution. These surface properties have to be documented in situ to test models for the origin of minerals that are key markers of environmental evolution on Mars.

Together, larger in situ stratigraphic datasets on paleoenvironments will help understand how their nature and habitability persisted or evolved in conjunction with other early global processes such as volcanic degassing and loss of Mars' atmosphere to space.

More details on potential outcomes of paleoenvironmental investigations on Mars in the PSDS white paper of B. Horgan et al. 


\section{The potential of mid-air deployed (MAD) rotorcrafts}

Mid-Air Deployment (MAD) is a set of technologies that enable the transition of a rotorcraft from a stowed configuration in the aeroshell during atmospheric descent to stable controlled flight above the surface before landing. MAD is planned for Dragonfly on Titan in 2034 and the necessary technology for Mars is currently being developed (Delaune et al., 2020).

We advocate for the use of MAD rotorcrafts, offering unprecedented mobility and affordability relative to rover-based exploration, while complementary to existing datasets and mission plans.

Multiple factors support the development of MAD rotorcraft missions for Mars at this time:

- MAD eliminates the need for traditional EDL equipment. This saves $100+\mathrm{kg}$ in entry mass and reduces the complexity of the aeroshell design. This simpler and lighter design is likely to reduce the risk of mission failure, as well as mission costs.

- Reduced mass (below $200 \mathrm{~kg}$ ) enables faster deceleration on entry and landing at elevations higher than current EDL capabilities (potentially > +4 km MOLA), therefore accessing the vast geological record of the highlands.

- Cost reduction enables a significant competitive advantage for a future Discovery solicitation or if a new class is introduced between SIMPLEx and Discovery.

- Airborne mobility enables strategically targeting the best exposures and a diversity of geological features on a regional scale, a key capability to advance in situ science, and to address several of the science questions outlined above with one low cost mission.

- A rotorcraft operates at various scales with both landed and in-flight observations over entire regions, bridging the gap between orbital maps and detailed in situ analyses.

- The Ingenuity Mars helicopter (flown with the Mars 2020 Perseverance rover) is a technical demo that should test flight capabilities in 2021. Fully-autonomous rotorcraft flights reduce operating costs in comparison to partially-autonomous rovers.

- Decades of experience in in situ instrumentation offer a range of readily available lightweight capabilities and new avenues for further miniaturization.

- The additional data on the geological record in key areas (Fig. 1), all achievable by using MAD rotorcrafts, will provide critical context for the interpretation of future sample analyses on Earth from Jezero crater.

- Long-term cost-intensive programs such as sample return, as well as missions to other destinations in the solar system (Artemis, Europa Clipper, et al.) require attractive and lowcost alternatives to further advance Mars science in the next decade.

A MAD rotorcraft could carry lightweight payloads (Young et al., 2020, see PSDS white paper by J. Bapst et al.) such as cameras, magnetometers, accelerometers, miniaturized near-infrared or thermal-infrared spectrometers as well as geochemical instruments (e.g. X-ray fluorescence, massspectrometers), similar to existing rover instruments and therefore enabling cross-comparisons of datasets.

A rotorcraft carrying such payload to previously unreachable locations has the potential to perform key observations related to multiple outstanding questions on the geological record of Mars (Fig. 1, 2), at an affordable cost, and to bridge the gap between orbital and rover-based datasets. 

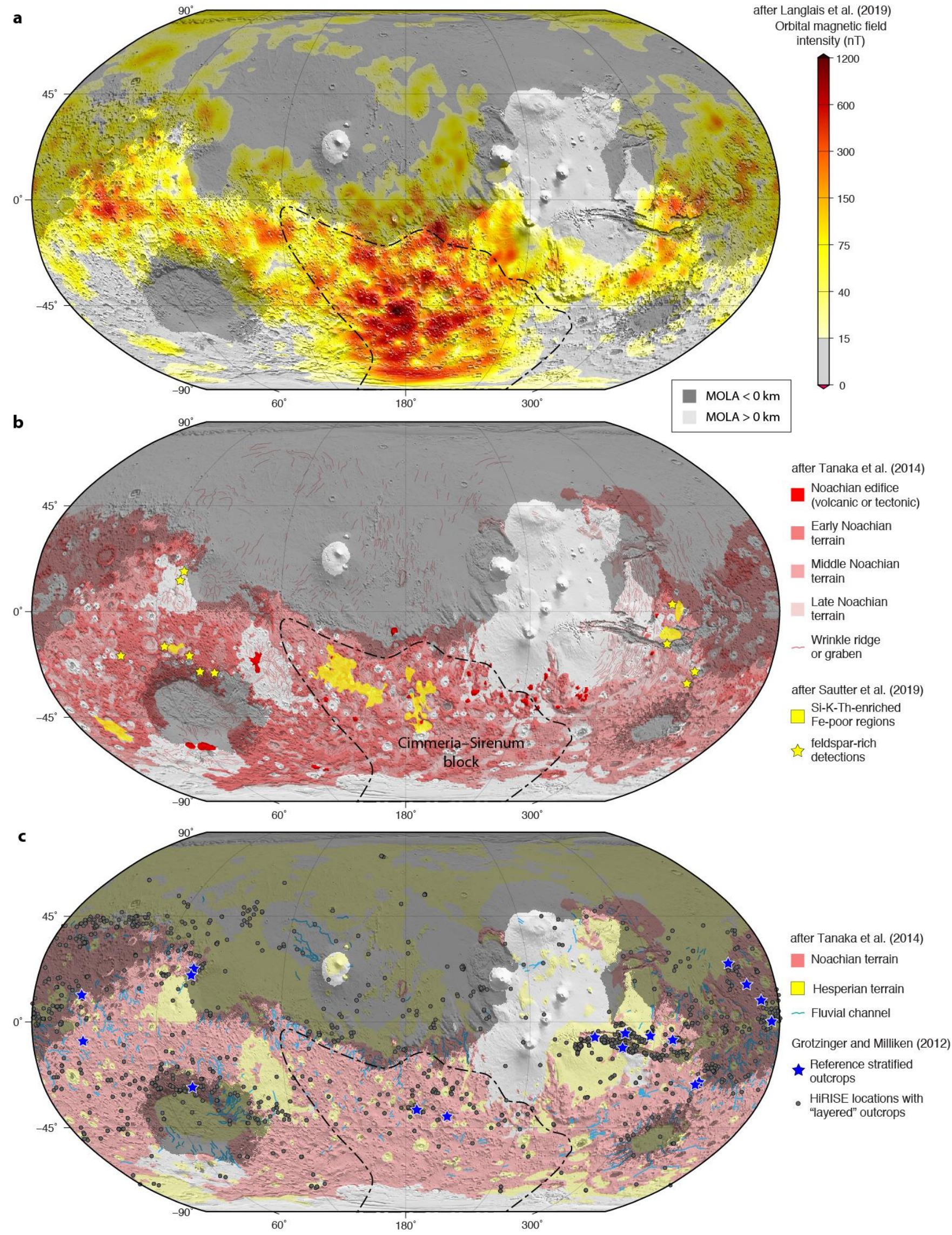
Figure 2 (previous page): Mid-air deployed (MAD) helicopters can land above current EDL technologies, at MOLA $>0 \mathrm{~km}$, a decisive advantage to investigate the record of: (a) paleomagnetism, this map of crustal magnetic field modeled at $135 \mathrm{~km}$ altitude (based on orbital measurements by MGS and MAVEN), but the strength and character of corresponding crustal magnetic fields near the surface is still poorly constrained due to lack of low-altitude observations. (b) Crust formation, CimmeriaSirenum block after Bouley et al. (2020), Si-K-Th enriched regions from Sautter et al. (2019); and (c) paleoenvironments, where black dots correspond to stratified deposits observed in HiRISE data.

Acknowledgements: Part of this research was carried out at the Jet Propulsion Laboratory, California Institute of Technology, under a contract with the National Aeronautics and Space Administration (80NM0018D0004).

\section{References:}

Delaune J., Rapin W., Izraelevitz J., Sklyanskiy E., et al. (2020) Enabling Mars Highlands Exploration By a Mid-AirDeployed Helicopter, Accepted in AIAA ASCEND Conference.

Andrews-Hanna, J. C., Zuber, M. T., \& Banerdt, W. B. (2008). The Borealis basin and the origin of the martian crustal dichotomy. Nature, 453(7199), 1212-1215. https://doi.org/10.1038/nature07011

Anguita, F., Fernández, C., Cordero, G., Carrasquilla, S., Anguita, J., Núñez, A., et al. (2006). Evidences for a Noachian-Hesperian orogeny in Mars. Icarus, 185(2), 331-357. https://doi.org/10.1016/j.icarus.2006.07.026

Baratoux, D., Samuel, H., Michaut, C., Toplis, M. J., Monnereau, M., Wieczorek, M., et al. (2014). Petrological constraints on the density of the Martian crust. Journal of Geophysical Research: Planets, 119(7), 17071727. https://doi.org/10.1002/2014JE004642

Bouley, S., Keane, J. T., Baratoux, D., Langlais, B., Matsuyama, I., Costard, F., et al. (2020). A thick crustal block revealed by reconstructions of early Mars highlands. Nature Geoscience, 13(2), 105-109. https://doi.org/10.1038/s41561-019-0512-6

Carter, J., \& Poulet, F. (2013). Ancient plutonic processes on Mars inferred from the detection of possible anorthositic terrains. Nature Geoscience, 6(12), 1008-1012. https://doi.org/10.1038/ngeo1995

Citron, R. I., Manga, M., \& Tan, E. (2018). A hybrid origin of the Martian crustal dichotomy: Degree-1 convection antipodal to a giant impact. Earth and Planetary Science Letters, 491, 58-66. https://doi.org/10.1016/j.epsl.2018.03.031

Dohm, J. M., Anderson, R. C., Williams, J.-P., Ruiz, J., McGuire, P. C., Buczkowski, D. L., et al. (2009). Claritas rise, Mars: Pre-Tharsis magmatism? Journal of Volcanology and Geothermal Research, 185(1), 139-156. https://doi.org/10.1016/j.jvolgeores.2009.03.012

Ehlmann, B. L., Anderson, F. S., Andrews-Hanna, J., Catling, D. C., Christensen, P. R., Cohen, B. A., et al. (2016). The sustainability of habitability on terrestrial planets: Insights, questions, and needed measurements from Mars for understanding the evolution of Earth-like worlds. Journal of Geophysical Research: Planets, 121(10), 1927-1961. https://doi.org/10.1002/2016JE005134

Ehlmann, Bethany L., \& Edwards, C. S. (2014). Mineralogy of the Martian Surface. Annual Review of Earth and Planetary Sciences, 42(1), 291-315. https://doi.org/10.1146/annurev-earth-060313-055024

Grotzinger, J. P., \& Milliken, R. E. (Eds.). (2012). Sedimentary Geology of Mars. SEPM (Society for Sedimentary Geology). https://doi.org/10.2110/pec.12.102

Johnson, C. L., Mittelholz, A., Langlais, B., Russell, C. T., Ansan, V., Banfield, D., et al. (2020). Crustal and timevarying magnetic fields at the InSight landing site on Mars. Nature Geoscience, 13(3), 199-204. https://doi.org/10.1038/s41561-020-0537-x

Langlais, B., Thébault, E., Houliez, A., Purucker, M. E., \& Lillis, R. J. (2019). A New Model of the Crustal Magnetic Field of Mars Using MGS and MAVEN. Journal of Geophysical Research: Planets, 124(6), 1542-1569. https://doi.org/10.1029/2018JE005854

Mittelholz, A., Johnson, C. L., Feinberg, J. M., Langlais, B., \& Phillips, R. J. (2020). Timing of the martian dynamo: New constraints for a core field 4.5 and $3.7 \mathrm{Ga}$ ago. Science Advances, 6(18), eaba0513. https://doi.org/10.1126/sciadv.aba0513

Sautter, V., Toplis, M. J., Wiens, R. C., Cousin, A., Fabre, C., Gasnault, O., et al. (2015). In situ evidence for continental crust on early Mars. Nature Geoscience, 8(8), 605-609. https://doi.org/10.1038/ngeo2474

Sautter, V., Payré, V., Baratoux, D., Toplis, M., Cousin, A., Bouley, S., et al. (2019). Remanant of Early Noachian Crust on Mars from Martian Meteorites, In Situ and Remote Sensing Data. Mars 9th IC, 6020.

Stanley, S., Elkins-Tanton, L., Zuber, M. T., \& Parmentier, E. M. (2008). Mars' Paleomagnetic Field as the Result of a Single-Hemisphere Dynamo. Science, 321(5897), 1822-1825. https://doi.org/10.1126/science.1161119

Wray, J. J., Hansen, S. T., Dufek, J., Swayze, G. A., Murchie, S. L., Seelos, F. P., et al. (2013). Prolonged magmatic activity on Mars inferred from the detection of felsic rocks. Nature Geoscience, 6(12), 1013-1017. https://doi.org/10.1038/ngeo1994

Young, L.A., Delaune, J., Johnson, W., Withrow, et al. (2020). Design Considerations for a Mars Highland Helicopter. Accepted in AIAA ASCEND Conference. 